\title{
Prevalence and pattern of non-communicable diseases among elderly in a sub-urban area of Delhi
}

Tushar Prabhakar ${ }^{1}$, Manish Kumar Goel ${ }^{2}$, Anita Shankar Acharya ${ }^{3}$, Sanjeev Kumar Rasania ${ }^{4}$

${ }^{1}$ Junior Resident, Department of Community Medicine, Lady Hardinge Medical College, New Delhi, India; ${ }^{2}$ Professor, Department of Community Medicine, Lady Hardinge Medical College, New Delhi, India; ${ }^{3}$ Professor, Department of Community Medicine, Lady Hardinge Medical College, New Delhi, India; ${ }^{4}$ Director Professor and Head, Department of Community Medicine, Lady Hardinge Medical College, New Delhi, India

\begin{tabular}{|c|c|c|c|c|c|c|c|}
\hline Abstract & Introduction & Methodology & Results & Conclusion & References & Citation & Tables/ Figures \\
\hline
\end{tabular}

\section{Corresponding Author}

Dr. Manish Kumar Goel, Professor, Department of Community Medicine, Lady Hardinge Medical

College, New Delhi-110001 India

E Mail ID: drmanishgoel2000@yahoo.co.in

\section{Citation}

Prabhakar T, Goel MK, Acharya AS, Rasania SK. Prevalence and pattern of non-communicable diseases among elderly in a sub-urban area of Delhi. Indian J Comm Health. 2021;33(1):75-81. https://doi.org/10.47203/IJCH.2021.v33i01.010

Source of Funding: Nil Conflict of Interest: None declared

\section{Article Cycle}

Received: 15/01/2021; Revision: 23/02/2021; Accepted: 04/03/2021; Published: 31/03/2021

This work is licensed under a Creative Commons Attribution 4.0 International License.

\section{Abstract}

Background: With increasing proportion of geriatric population across societies, the occurrence and prevalence of non-communicable diseases has been steadily increasing as well. The study tries to showcase the pattern and proportion of NCDs among the elderly population in a sub-urban part of Delhi. Aim \& Objective: To assess the prevalence and study the morbidity profile of NCDs among geriatric population of Delhi. Materials \& Methods: A community based cross sectional study was done in 350 elderly participants in Mehrauli, Delhi. Data was collected using a semi-structured questionnaire. Detailed general and systemic examination was also done. Results: A total of $87.4 \%$ of the study population was suffering from at least one NCD; $68 \%$ were having an already known NCD(s) while $19.4 \%$ were newly diagnosed during the study. 2.41 NCDs were found per patient. The prevalence of hypertension was $58 \%$, $49.4 \%$ suffered from senile cataract, $32.9 \%$ had osteoarthritis, $30.3 \%$ had diabetes mellitus, and $26.9 \%$ had obesity. Hypertension and diabetes mellitus together were present in $18.3 \%$ while the combination of hypertension, diabetes mellitus and obesity was seen in $9.4 \%$ of the study participants. Conclusion: Burden of NCDs among the elderly was notably high with a large proportion of them having multimorbidity. It gets important to focus on preventive measures to delay the onset and stem the progression of NCDs to facilitate healthy ageing.

\section{Keywords}

Non-Communicable Diseases; Elderly; India

\section{Introduction}

World population ageing is swelling; the proportion of older persons has been rising steadily, from one in fifteen in 1950 to one in seven currently, with that figure expected to double by 2050. Globally the population of older persons is growing at a considerably faster rate compared to the population as a whole.(1)

Progression from childhood to adulthood and eventually to old age naturally results in a large diversity and inequity with respect to determinants of health. This makes the elderly one of the most 
vulnerable and high-risk groups in terms of health

status.

Reform of the medical and health system and increased life expectancy of patients, both give rise to increased prevalence of Non-communicable diseases (NCDs), especially among the elderly. NCDs among the geriatric age group is an area that requires special focus as morbidity impact is more accentuated and disabling and often require multiple drug treatment, physiotherapy, and long-term rehabilitation.

The prevalence pattern of NCDs is closely related to economy, society, population, behaviour, environment, type of illness and so forth.

This study aims to estimate the prevalence of select non-communicable diseases and their pattern among the elderly residing in a sub-urban locality of Delhi.

\section{Aims \& Objectives}

1. To assess the prevalence of NCDs among elderly over 60 years of age in Delhi.

2. To study the morbidity profile of NCDs among elderly over 60 years of age in Delhi.

\section{Material \& Methods}

A community based observational cross sectional study was conducted among study participants in Mehrauli area of Delhi (a field practice area of the Dept. of Community Medicine in Lady Hardinge Medical College).

The study was done among the elderly population over 60 years of age who had been residing in the study area for at least a year and were willing to participate. Those who were seriously moribund or bed ridden or were unable to respond to the interview due to physically limiting disabilities were excluded.

The sample size was calculated using $N=Z^{2} p q / l^{2}$. Taking $64 \%(2,3)$ as prevalence of NCDs, the sample size calculated for $95 \%$ level of significance, $10 \%$ allowable error, and design effect $=1.5$ was found to be 337 participants and that was rounded off to 350 . Three out of eight wards of Mehrauli area were selected randomly and subsequently systematic random sampling was done. The collective approximate population of the selected wards was found to be around 34,000 . Sampling frame that included the elderly $>60$ years was assessed using national population percentage of elderly $(8.6 \%$ of total population). It was found that every eighth house needed to be visited in order to fulfil the sample size. The first house was decided by selecting a random number between 1 and 10 using lottery method and visiting the house that corresponded with the number. In case there were two or more elderly in a household, only one was randomly selected for the study. In case, there was no elderly person in a household, the next house was selected. In case a house was found locked even after three consecutive visits, the next house was selected. Whenever a crossroad came up, the road to the left was taken. The interview and examination was conducted by the first author and average time taken for it was around 30 minutes. The data collection was done from January to December 2019.

A self-designed, pre-tested, semi-structured interview schedule was used which included sociodemographic particulars, screening for selected NonCommunicable Diseases (Diabetes mellitus, hypertension, osteoarthritis, senile cataract, obesity) and other known NCDs. It was followed with detailed general and systemic examination. Operational definitions used for diagnosing new cases were-

Diabetes Mellitus- In asymptomatic patients if the fasting plasma glucose (FPG) value is $\geq 126 \mathrm{mg} / \mathrm{dl}$ ) or if the casual plasma glucose value is $\geq 200 \mathrm{mg} / \mathrm{dl}$. Symptomatic patients were those having increased frequency of urination, thirst and/or hunger. First Random blood Glucose of the participants was measured. In case RBS $\leq 200 \mathrm{mg} / \mathrm{dl}$, the individual was classified as Normoglycemic. If RBS $\geq 200 \mathrm{mg} / \mathrm{dl}$ and symptoms were present diagnosis of diabetes mellitus was confirmed. If $\mathrm{RBS} \geq 200 \mathrm{mg} / \mathrm{dl}$ and symptoms were not present, Fasting Blood Glucose was measured the next day to confirm the diagnosis. If FBS $\geq 126 \mathrm{mg} / \mathrm{dl}$ diagnosis of diabetes mellitus was confirmed.(4)

Hypertension- According to JNC 8 Blood Pressure Guideline, in people above 60 years, pharmacological therapy should be started at a BP of $\geq 150 / 90 \mathrm{~mm} \mathrm{Hg}$. In diabetic population aged 18 years or older, the target blood pressure is $<140 / 90$ $\mathrm{mm} \mathrm{Hg}$. Average blood pressure higher than the aforementioned cut-offs was considered to diagnose Hypertension.(5)

Obesity- By measuring Body Mass Index (BMI) participants were categorized as underweight $(<18.5$ $\left.\mathrm{kg} / \mathrm{m}^{2}\right)$, normal or lean BMI $\left(18.5-22.9 \mathrm{~kg} / \mathrm{m}^{2}\right)$, overweight $\left(23.0-24.9 \mathrm{~kg} / \mathrm{m}^{2}\right)$ and obese $(\geq 25$ $\mathrm{kg} / \mathrm{m}^{2}$ ) based on the revised consensus guidelines for India.(6) 
Osteoarthritis- History of any significant pain and restriction in movement of large joints was used to diagnose osteoarthritis. Severity was assessed using WOMAC and KATZ tool.(7)

Senile Cataract- Torch Light examination was used to assess the presence of senile cataract. Greyish to white discolouration of lens with or without iris shadow was considered positive for senile cataract. Data collected from proforma was coded and entered in SPSS. All quantitative variables were analysed in terms of mean and standard deviation while qualitative variables were analysed through proportions.

\section{Results}

A total of 350 elderly above 60 years were enrolled in the study of whom 191 (54.6\%) were women and 159 (45.4\%) were men. [Table 1] Mean age of the study participants was $68.26 \pm 6.45$ years (Range $=$ $60-86$ years). Almost two-thirds [ $n=231(66 \%)]$ of the study group belonged to young old (60-69 years) age group. More than two-thirds [ $n=243(69.4 \%)]$ were currently married; the remaining were widowed. More than one-third [ $n=118$ (33.7\%)] of the participants had no formal education whereas 115 (32.9\%) had completed at least high school. More than half [ $n=188(53.7 \%)]$ of the study participants belonged to upper middle $(52.9 \%)$ or upper $(0.9 \%)$ class. Majority of the study participants [ $n=250(71.4 \%)]$ were living in joint families while $2.9 \%$ were living by themselves.

A total of 306 ie. $87.4 \%$ of the study population was suffering from at least one NCD. [Table 2] More than two-thirds $[n=238(68 \%)]$ of the study participants were having an already known $\mathrm{NCD}(\mathrm{s})$ while almost one-fifth [ $n=68(19.4 \%)]$, though having an NCD, were not aware of it. A higher proportion of female participants had an already diagnosed NCD $[n=148$ $(77.5 \%)]$ as compared to men [ $n=90(56.6 \%)]$. Prevalence of NCD increased with age, from $77.0 \%$ $(n=101)$ in $60-65$ years age group to $100 \%$ in 76 years and above. It was seen that 238 study participants with known NCDs had a total of 428 NCDs i.e. 1.79 NCD per patient. At the end of the study it was found that the 306 participants had a total of 736 NCDs; that is 2.41 NCDs per patient. Of these, 136 male participants had 263 NCDs (1.93 NCD per patient) while 170 female participants had 473 NCDs $(2.78$ NCD per patient). The proportion of study participants having hypertension was $58 \%(n=203)$ while 173 (49.4\%) suffered from senile cataract; 115
(32.9\%) had osteoarthritis, 106 (30.3\%) had diabetes mellitus, and 96 (26.9\%) had obesity. [Table 3 ]

At the beginning of the study, of the 238 study participants who had an NCD, 103 (43.3\%) had a single NCD, while $138(56.7 \%)$ had two or more NCDs. During the study 67 of those with a single NCD were diagnosed to have at least one another NCD. In the 68 new patients who were identified during the study, close to two-thirds [ $n=44(64.7 \%)$ ] had a single NCD while the remaining had two or more. Overall, 80 out of the total 350 study participants $(22.9 \%)$ had a single NCD, while 226 (64.6\%) had two or more NCDs. Hypertension and diabetes mellitus together were present in $64(18.3 \%)$ of the study population while the combination of hypertension, diabetes mellitus and obesity was seen in $33(9.4 \%)$ of them.[Table 4] [Figure 1]

\section{Discussion}

With each passing day the relevance of the words 'population ageing' and 'non-communicable diseases' becomes greater. This can be ascribed directly to the fact that the numbers of both are going to increase in times to come and so is their degree of attribution. The present study focused on major non-communicable illnesses in the field practice area. Prevalence of known NCDs was assessed along with relevant screening for selected NCDs helped figure out the overall burden of these chronic morbidities.

Seven out of eight individuals ie. 87\% participants in our study were having an NCD. The prevalence of common NCDs varied from $14.1 \%$ (8) to $98.2 \%$ (9) among studies conducted by various researchers in the past. However, studies from metro cities showed similar prevalence of NCDs among elderly- $87 \%$ in Chandigarh by Kaur et al(10) and $84 \%$ in Shimla by Sharma et al (11).

The total proportion of women having at least one NCD (89.0\%) was slightly higher than men (85.5\%). Longer life expectancy resulting in increased probability of getting a chronic disease could be a reason for the higher proportion among women.

A higher proportion of female participants had an already diagnosed NCD (77.5\%) as compared to men (56.6\%). This resulted in a larger fraction of apparently healthy male participants. This further resulted in a larger percentage of remaining male participants (66.67\%) being diagnosed as having an NCD during study. $51.2 \%$ of the previously healthy 

women were diagnosed as having an NCD during the study.

Occurrence of NCDs increases naturally as age progresses; this was also evident in this study wherein over $95 \%$ of the old and oldest old participants had at least one NCD. Participants belonging to the age group of $60-65$ years, while having the least overall prevalence of NCDs, also had least awareness regarding an existing NCD. Almost $50 \%$ of the presumed healthy participants ended up having an NCD.

Prevalence of NCDs showed little variation among those from different religious backgrounds. The overall prevalence of NCDs in this study didn't vary much according to level of literacy. However, it was seen that newly diagnosed NCDs was highest among illiterate (65.7\%) and lowest among those who had education up till high school or above (51.4\%). In this study, we found that lower level of education was associated with increased morbidity which could be due to over reporting. Similar results were found by Joshi et al (12) and Kaur et al (10).

All individuals who were living alone had an NCD while $87 \%$ of those living with family had one. It can be argued that psychological isolation and loneliness resulting from staying alone has an impact on the physical attributes and health.

Prevalence of NCDs among study participants was lower in families belonging to upper and uppermiddle classes (86.2\%) when compared to lowermiddle class (87.8\%) and upper-lower and lower classes (92.3\%). This could be attributed to the overall lifestyle choices that were presumably better among the higher classes. Similar results were found in studies by Kaur et al (10) where socio-economic status was responsible for occurrence of NCD (OR = $6.588,95 \% \mathrm{Cl}=2.404-18.049$, $\mathrm{p}$ value $<0.001$ )

Hypertension was the most prevalent chronic disease, followed by senile cataract, osteoarthritis, diabetes mellitus and obesity. Similar order of proportion of selected NCDs was seen in studies by Bhat et al (2) and Joshi et al (12). A total of $6.7 \%$ $(n=16)$ of the study individuals had hypothyroidism, $5.0 \%(n=12)$ each suffered from asthma and CAD, two participants $(0.8 \%)$ had COPD and one patient was a known case of Schizophrenia.

The proportion of those having multi-morbidity has been on the rise and is becoming a serious public health concern. Close to one in five people in our study [ $n=64(18.3 \%)]$ had both diabetes mellitus and hypertension while every tenth individual $[n=33$
(9.4\%)] had a triad of diabetes mellitus, hypertension and obesity. This exponentially increases the risk of getting cardiovascular diseases and stroke in future. The findings in our study were higher as compared to Kapil et al (13) who conducted the study in Nainital where $8.6 \%$ of the study participants had both diabetes mellitus and hypertension. This could be due to the fact that individual prevalence of diabetes mellitus and hypertension was higher in our study population

\section{Conclusion}

The study found that the burden of noncommunicable diseases among the elderly was notably high and universally present among all strata of the study population.

A fifth of the total study participants were unaware of their illness and were diagnosed for the first time during the study. Multi-morbidity was quite common and in the study it was found to be 2.41 per patient. NCDs, being universally present among all geriatric strata, calls for new ingenious ways to deal with them.

It is also important to identify types of NCDs that have similar environmental and host attributes and onus should be to focus on preventive health measures that have an umbrella effect on such NCDs.

\section{Recommendation}

Increasing awareness among illiterates by using innovative IEC methods, including grass root level workers in screening and service delivery, having separate NCD and geriatric clinics are all ways in which we can hope to reduce occurrence and delay progression of NCDs.

\section{Limitation of the study}

The exact prevalence of some relatively common NCDs like Hypothyroidism, asthma, COPD etc. could not be assessed due to diagnostic constraints.

\section{Relevance of the study}

The study tries to bring forth the distribution pattern of common NCDs across different strata of elderly society and throw light on the prevalence of hidden NCDs and the burden of multimorbidity.

\section{Authors Contribution}

TP: Conception, design, acquisition of data and analysis, drafting and critical revision of article. MKG: Conception, design, analysis, critical revision and final approval of article. ASA: Conception, design, analysis, critical revision and final approval of article. 
INDIAN JOURNAL OF COMMUNITY HEALTH / VOL 33 / ISSUE NO 01 / JAN- MAR 2021 SKR: Analysis, critical revision and final approval of article

\section{References}

1. Wongboonsin $\mathrm{P}$, Wongboonsin $\mathrm{K}$, Demographic Dividend and the Future of Asia. In: Ochiai E, Hosoya LA, editors. Transformation of the Intimate and the Public in Asian Modernity. 1st ed. Leiden. Brill; 2014:91-115

2. Bhat S, Kumar S. Study on health care seeking behaviour among elderly in rural area. Int J Med Sci Public Health. 2017;6:350-2.

3. Kumar D, Kumari R, Shankar H. Health Status and Health Seeking Behaviour of Rural Geriatric Population of Varanasi District, India. Int J Med Sci Public Health. [Internet]. 2015; 4(12): 1711-4. Available from: doi:10.5455/ijmsph.2015.22052015353

4. World Health Organization. Screening for type 2 diabetes. Report of a World Health Organization and International Diabetes Federation meeting. Geneva. [Internet] World Health Organization; 2003. Available from: http://www.who.int/iris/handle/10665/68614 [cited 2021 Feb 20]

5. James PA, Oparil S, Carter BL, Cushman WC, DennisonHimmelfarb C, Handler J, Lackland DT, LeFevre ML, MacKenzie TD, Ogedegbe O, Smith SC Jr, Svetkey LP, Taler SJ, Townsend RR, Wright JT Jr, Narva AS, Ortiz E. 2014 evidence-based guideline for the management of high blood pressure in adults: report from the panel members appointed to the Eighth Joint National Committee (JNC 8). JAMA. 2014;311(5):507-20. doi: 10.1001/jama.2013.284427. Erratum in: JAMA. 2014 May 7;311(17):1809. PMID: 24352797.[PubMed].

6. Misra A, Chowbey P, Makkar BM, Vikram NK, Wasir JS, Chadha D, Joshi SR, Sadikot S, Gupta R, Gulati S, Munjal YP; Concensus Group. Consensus statement for diagnosis of obesity, abdominal obesity and the metabolic syndrome for
[Prevalence and pattern...] | Prabhakar T et al Asian Indians and recommendations for physical activity, medical and surgical management. J Assoc Physicians India. 2009;57:163-70. PMID: 19582986.[PubMed].

7. CRD - Research - Health Instruments [Internet]. Pune: Rheumatology India [cited 2020 Jun 20]. Available from http://rheumatologyindia.org/research_health.htm

8. Hegde SKB, Agrawal T, Farah F, Amar DS. Factors Associated with Health Seeking Behaviour Regarding Noncommunicable Diseases Among Elderly in A Rural Community in Karnataka (India). Indian Journal of Gerontology. 2015; 29(3):283-93.

9. Warbhe PA, Warbhe R. Morbidity Profile, Health Seeking Behaviour And Home Environment Survey For Adaptive Measures In Geriatric Population - Urban Community Study. Int J Med Res Health Sci. 2015;4(4):778-82.

10. G. Kaur, Bansal R, Anand T, Kumar A, Singh J. Morbidity profile of noncommunicable diseases among elderly in a city in North India. Clin Epidemiol Glob Health. 2019;7(1):29-34.

11. Sharma D, Mazta SR, Parashar A. Morbidity Pattern and Health-seeking Behavior of Aged Population residing in Shimla Hills of North India: A Cross-Sectional Study. J Family Med Prim Care. 2013;2(2):188-93. doi: 10.4103/22494863.117421. PMID: 24479077; PMCID: PMC3894043. [PubMed].

12. Joshi K, Kumar R, Avasthi A. Morbidity profile and its relationship with disability and psychological distress among elderly people in Northern India. Int J Epidemiol. 2003;32(6):978-87. doi: 10.1093/ije/dyg204. PMID: 14681260. [PubMed].

13. Kapil U, Khandelwal R, Ramakrishnan L, Khenduja P, Gupta A, Pandey RM, Upadhyay AD, Belwal RS. Prevalence of hypertension, diabetes, and associated risk factors among geriatric population living in a high-altitude region of rural Uttarakhand, India. J Family Med Prim Care. 2018;7(6):1527-1536. doi: 10.4103/jfmpc.jfmpc_108_18. PMID: 30613554; PMCID: PMC6293909.[PubMed].

\section{Tables}

TABLE 1 SOCIO-DEMOGRAPHIC VARIABLES AMONG STUDY PARTICIPANTS $(\mathrm{N}=350)$

\begin{tabular}{|c|c|c|c|c|c|c|c|}
\hline \multicolumn{2}{|c|}{ Socio-demographic character } & \multicolumn{2}{|c|}{ Men } & \multicolumn{2}{|c|}{ Women } & \multicolumn{2}{|c|}{ Total } \\
\hline & & $\mathbf{n}$ & $\%$ & $\mathbf{n}$ & $\%$ & $\mathbf{N}$ & $\%$ \\
\hline \multicolumn{2}{|c|}{ Total participants } & 159 & 45.4 & 191 & 54.6 & 350 & 100 \\
\hline \multirow{3}{*}{$\begin{array}{l}\text { Age } \\
\text { (in completed years) }\end{array}$} & $60-69$ & 109 & 31.1 & 122 & 34.9 & 231 & 66.0 \\
\hline & $70-79$ & 39 & 11.2 & 55 & 15.7 & 94 & 26.9 \\
\hline & $\geq 80$ & 11 & 3.1 & 14 & 4.0 & 25 & 7.1 \\
\hline \multirow[t]{7}{*}{ Level of Literacy } & Illiterate & 41 & 11.7 & 77 & 22.0 & 118 & 33.7 \\
\hline & Literate, less than middle school & 26 & 7.4 & 38 & 10.9 & 64 & 18.3 \\
\hline & Middle school & 32 & 9.1 & 21 & 6.0 & 53 & 15.1 \\
\hline & High school certificate & 13 & 3.7 & 22 & 6.3 & 35 & 10.0 \\
\hline & Higher Secondary & 17 & 4.9 & 18 & 5.1 & 35 & 10.0 \\
\hline & Graduate & 28 & 8.0 & 14 & 4.0 & 42 & 12.0 \\
\hline & Post Graduate/ Profession & 2 & 0.6 & 1 & 0.3 & 3 & 0.9 \\
\hline \multirow[t]{3}{*}{ Socio-economic status } & Lower \& Upper Lower & 12 & 3.4 & 27 & 7.7 & 39 & 11.2 \\
\hline & Lower Middle & 42 & 12.0 & 81 & 23.1 & 123 & 35.1 \\
\hline & Upper Middle \& Upper & 105 & 30.0 & 83 & 23.7 & 188 & 53.7 \\
\hline \multirow[t]{3}{*}{ Type of family } & Nuclear & 39 & 11.1 & 51 & 14.6 & 90 & 25.7 \\
\hline & Joint/ Extended & 119 & 34.0 & 131 & 37.4 & 250 & 71.4 \\
\hline & Living alone & 1 & 0.3 & 9 & 2.6 & 10 & 2.9 \\
\hline
\end{tabular}




\section{TABLE 2 PREVALENCE OF COMMON NCDS AMONG STUDY PARTICIPANTS ( $\mathrm{N}=350)$}

\begin{tabular}{|c|c|c|c|c|c|}
\hline \multicolumn{3}{|c|}{$\begin{array}{r}\text { Total number of } \\
\text { participants }\end{array}$} & $\begin{array}{r}\text { Participants with } \\
\text { known NCDs }\end{array}$ & $\begin{array}{r}\text { Participants with } \\
\text { newly diagnosed } \\
\text { NCDs }\end{array}$ & $\begin{array}{r}\text { Total number of } \\
\text { participants with } \\
\text { NCDs }\end{array}$ \\
\hline \multirow[t]{2}{*}{ Gender } & Men & 159 & 90 (56.6) & 46 (28.9) & $136(85.5)$ \\
\hline & Women & 191 & 148 (77.5) & $22(11.5)$ & $170(89.0)$ \\
\hline \multirow{3}{*}{$\begin{array}{l}\text { Age (in } \\
\text { completed years) }\end{array}$} & $60-69$ & 237 & $144(60.7)$ & $54(22.8)$ & $198(83.5)$ \\
\hline & $70-79$ & 89 & $70(78.7)$ & $14(15.7)$ & $84(94.4)$ \\
\hline & $\geq 80$ & 24 & $24(100)$ & 0 & $24(100)$ \\
\hline \multirow[t]{6}{*}{ Level of Literacy } & $\begin{array}{l}\text { Graduate/ post } \\
\text { graduate }\end{array}$ & 45 & $30(66.7)$ & $11(24.4)$ & 41 (91.1) \\
\hline & Higher Secondary & 35 & $29(82.9)$ & $1(2.9)$ & $30(85.8)$ \\
\hline & $\begin{array}{l}\text { High school } \\
\text { certificate }\end{array}$ & 35 & $21(60.0)$ & $6(17.1)$ & 27 (77.1) \\
\hline & Middle school & 53 & $35(66.0)$ & $11(20.8)$ & $46(86.8)$ \\
\hline & $\begin{array}{l}\text { Literate, less than } \\
\text { middle school }\end{array}$ & 64 & $40(62.5)$ & $16(25.0)$ & $56(87.5)$ \\
\hline & Illiterate & 118 & $83(70.3)$ & $23(19.5)$ & $106(89.8)$ \\
\hline \multirow[t]{3}{*}{ Type of family } & Joint & 250 & $172(68.8)$ & $49(19.6)$ & $221(88.4)$ \\
\hline & Nuclear & 90 & $58(64.4)$ & 17 (18.9) & $75(83.3)$ \\
\hline & Living alone & 10 & $8(80.0)$ & $2(20.0)$ & $10(100)$ \\
\hline \multirow[t]{4}{*}{$\begin{array}{l}\text { Socio-economic } \\
\text { status }\end{array}$} & $\begin{array}{l}\text { Upper + Upper- } \\
\text { Middle }\end{array}$ & 188 & $138(73.4)$ & $24(12.8)$ & $162(86.2)$ \\
\hline & Lower-Middle & 123 & 75 (61.0) & $33(26.8)$ & $108(87.8)$ \\
\hline & $\begin{array}{l}\text { Lower + Upper- } \\
\text { Lower }\end{array}$ & 39 & $25(64.1)$ & $11(28.2)$ & $36(92.3)$ \\
\hline & Total & 350 & $238(68)$ & 68 (19.4) & $306(87.4)$ \\
\hline
\end{tabular}

TABLE 3 DISTRIBUTION OF NCDS AMONG STUDY PARTICIPANTS ( $\mathrm{N}=238$ )

\begin{tabular}{|l|r|r|r|r|r|r|r|} 
& \multicolumn{1}{|c|}{ DM } & HTN & $\begin{array}{r}\text { Osteo- } \\
\text { arthritis }\end{array}$ & Cataract & Obesity & Others* & Total \\
\hline Already known NCDs & 88 & 147 & 66 & 82 & 2 & 43 & 428 \\
(238 participants) & $(36.9 \%)$ & $(61.8 \%)$ & $(27.7 \%)$ & $(34.5 \%)$ & $(0.8 \%)$ & & \\
\hline Newly diagnosed NCDs & 18 & 56 & 49 & 91 & 94 & & 308 \\
\hline Total NCDs & $(6.9 \%)$ & $(27.6 \%)$ & $(17.3 \%)$ & $(33.9 \%)$ & $(27.0 \%)$ & & \\
(306 participants) & 106 & 203 & 115 & 173 & 96 & 43 & 736 \\
\hline
\end{tabular}

*Others - hypothyroidism, asthma, CAD, COPD, Obesity, Schizophrenia

TABLE 4 DISTRIBUTION OF STUDY PARTICIPANTS ACCORDING TO NUMBER OF NCDS (N=238)

\begin{tabular}{|c|c|c|c|c|c|c|}
\hline \multirow[t]{2}{*}{ No. of NCDs } & \multicolumn{3}{|c|}{ Participants with known NCDs } & \multicolumn{3}{|c|}{ Participants with newly diagnosed NCDs } \\
\hline & $\begin{array}{r}\text { Men } \\
n=159\end{array}$ & $\begin{array}{r}\text { Women } \\
n=191\end{array}$ & $\begin{array}{r}\text { Total } \\
n=350\end{array}$ & $\begin{array}{r}\text { Men } \\
n=159\end{array}$ & $\begin{array}{r}\text { Women } \\
n=191\end{array}$ & $\begin{array}{r}\text { Total } \\
n=350\end{array}$ \\
\hline 1 & $\begin{array}{r}54 \\
(33.9)\end{array}$ & $\begin{array}{r}49 \\
(25.7)\end{array}$ & $\begin{array}{r}103 \\
(29.4)\end{array}$ & $\begin{array}{r}33 \\
(20.8)\end{array}$ & $\begin{array}{r}11 \\
(5.8)\end{array}$ & $\begin{array}{r}44 \\
(12.6)\end{array}$ \\
\hline 2 & $\begin{array}{r}33 \\
(20.8)\end{array}$ & $\begin{array}{r}60 \\
(31.4)\end{array}$ & $\begin{array}{r}93 \\
(26.6)\end{array}$ & $\begin{array}{r}10 \\
(6.3)\end{array}$ & $\begin{array}{r}7 \\
(3.7)\end{array}$ & $\begin{array}{r}17 \\
(4.9)\end{array}$ \\
\hline$>2$ & $\begin{array}{r}3 \\
(1.9)\end{array}$ & $\begin{array}{r}39 \\
(20.4)\end{array}$ & $\begin{array}{r}42 \\
(12.0)\end{array}$ & $\begin{array}{r}3 \\
(1.9)\end{array}$ & $\begin{array}{r}4 \\
(2.1)\end{array}$ & $\begin{array}{r}7 \\
(2.0)\end{array}$ \\
\hline Total & $\begin{array}{r}90 \\
(56.6)\end{array}$ & $\begin{array}{r}148 \\
(77.5)\end{array}$ & $\begin{array}{r}238 \\
(68.0)\end{array}$ & $\begin{array}{r}46 \\
(28.9)\end{array}$ & $\begin{array}{r}22 \\
(11.5)\end{array}$ & $\begin{array}{r}68 \\
(19.4)\end{array}$ \\
\hline
\end{tabular}

Percentages are given in bracket 


\section{Figures}

FIGURE 1 RADAR CHART SHOWING COMPARISON BETWEEN PREVALENCE OF KNOWN NCDS AND OVERALL PREVALENCE OF SELECTED NCDS

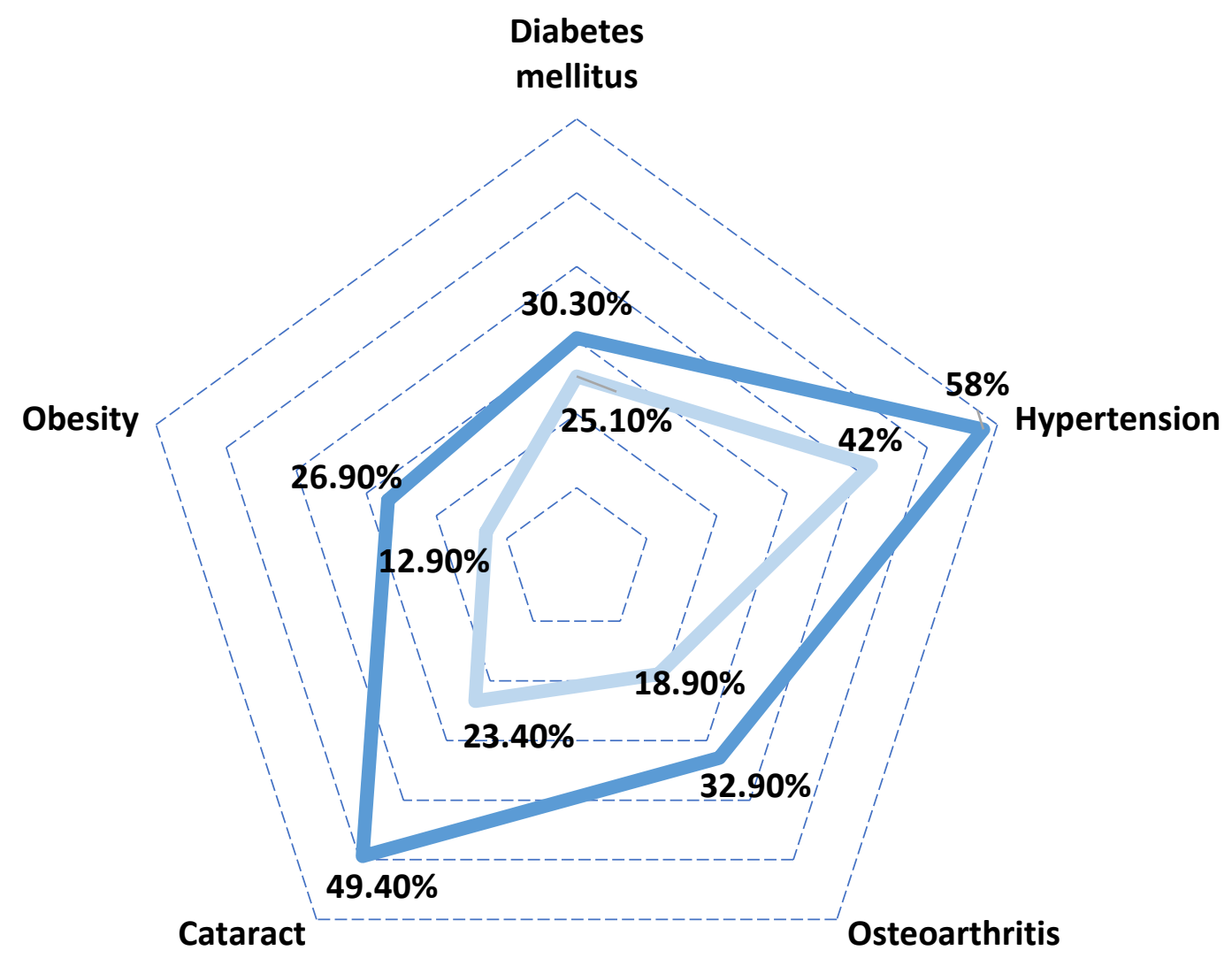

Prevalence of known NCDS Prevalence at the end of study 